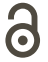

OPEN ACCESS

EDITORES

- Marcus Maia (UFRJ)

- Bruna Franchetto (UFRJ)

\section{AVALIADORES}

- Ana Vilacy Galucio (Museu Goeldi)

- Marcus Maia (UFRJ)

DATAS

- Recebido: 07/06/2020

- Aceito: 03/11/2020

- Publicado: 28/12/2020

\section{COMO CITAR}

CUNHA, Evandro L. T. P. (2020). A Web como ferramenta de suporte à preservação e à revitalização linguística Cadernos de Linguística, v. 1, n. 3, p. 01-14.

\title{
A WEB COMO FERRAMENTA DE SUPORTE À PRESERVAÇ̃̃o E À REVITALIZAÇÃO LINGUÍSTICA
}

\author{
Evandro L. T. P. Cunha (D) $\boldsymbol{X}$ \\ Faculdade de Letras - Universidade Federal de Minas Gerais (UFMG)
}

RESUMO

Nas primeiras décadas do século XXI, a Internet tem sido mais presente na vida cotidiana de um número cada vez maior de indivíduos no Brasil e no mundo - seja por meio de sites tradicionais, seja mediante o uso de redes sociais online e aplicativos de comunicação instantânea. No âmbito linguístico, a Web possui um papel paradoxal: ao mesmo tempo em que promove o acesso a línguas hegemônicas e de prestígio, ela oferece também novas possibilidades para a revitalização e a documentação de línguas ameaçadas de extinção. Para cada uma dessas línguas, ser utilizada na Internet significa ocupar um espaço de poder social, político e econômico considerado essencial no "mundo contemporâneo ocidental". O objetivo deste trabalho é traçar um panorama da presença de línguas minoritárias na Web, destacando sobretudo seu uso em redes sociais online e em plataformas colaborativas, além de outras iniciativas que exploram as possibilidades abertas por ferramentas virtuais para a preservação linguística. Por fim, conclui-se que a ampliação do acesso à Internet em todo o planeta é um caminho sem volta e que, portanto, é necessário utilizar com eficácia, competência e celeridade, a favor da preservação linguística, os novos recursos que são desenvolvidos.

\section{ABSTRACT}

In the first decades of the 21st century, the Internet has been more present in the daily lives of an increasing number of individuals in Brazil and in the world - either through traditional websites, or through the use 
of online social networks and instant communication applications. In the linguistic sphere, the Web has a paradoxical role: while promoting access to hegemonic and prestigious languages, it also offers new possibilities for the revitalization and documentation of languages threatened with extinction. For each of these languages, being used on the Internet means occupying which is considered an important space of social, political and economic power in the "contemporary western world". The aim of this paper is to outline an overview of the presence of minority languages on the Web, highlighting mainly their use in online social networks and in collaborative platforms, besides other initiatives that explore the possibilities opened by virtual tools for linguistic preservation. Finally, I conclude that the expansion of Internet access throughout the planet is a path of no return and, therefore, it is necessary to use effectively, competently and quickly, in favour of language preservation, the new resources that are developed.

\section{PALAVRAS-CHAVE}

Línguas Minoritárias; Preservação e Revitalização Linguística; Ferramentas Digitais; Redes Sociais Online.

\section{KEYWORDS}

Minority Languages; Language Preservation and Revitalization; Digital Tools; Online Social Networks. 


\section{INTRODUÇÃO}

Diversas fontes (p. ex., FISHMAN, 2001; HINTON, 2001) têm atestado os riscos sofridos por línguas minoritárias ao redor do mundo. De acordo com estimativas da UNESCO (MOSELEY, 2010), acredita-se que mais da metade das aproximadamente sete mil línguas faladas hoje no planeta estará extinta ao final do século XXI. No Brasil, tendo em vista o silenciamento que sofre a diversidade linguística, o cenário é especialmente preocupante: grande parte das línguas indígenas faladas no território nacional encontra-se fortemente ameaçada de desaparecimento no espaço de poucas gerações (cf. MOORE; GALUCIO; GABAS JR., 2008). O Gráfico 1 mostra o número de línguas faladas no Brasil classificadas em cada grau de ameaça na escala EGIDS: quanto mais à direita na escala, mais alto é o grau de ameaça de extinção'. Observa-se que boa parte das línguas faladas no Brasil está classificada nos níveis 8a a 9, isto é, já em processo avançado de desaparecimento.

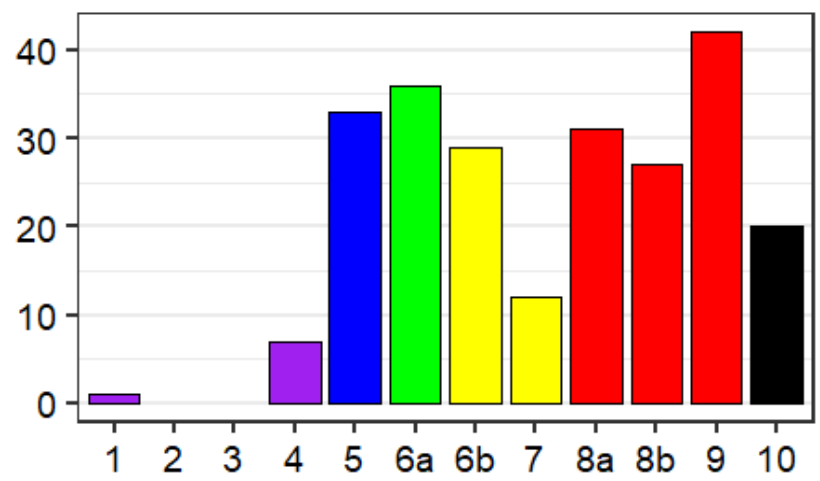

Gráfico 1. Número de línguas faladas no Brasil classificadas em cada grau de ameaça na escala EGIDS. Quanto mais à direita, maior o grau de ameça de extinção. Fonte: Eberhard, Simons e Fennig (2020). ${ }^{2}$

Diante dessa realidade, a crescente (e urgente) necessidade de se preservar e revitalizar línguas em risco de extinção exige a utilização de todas as ferramentas disponíveis. Sabe-se que um dos vários fatores que propiciam a difusão de línguas hegemônicas e de prestígio ${ }^{3}$ é a expansão do acesso à Internet. Já se demonstrou também que o ambiente digital deverá aumentar cada vez mais a desigualdade entre línguas majoritárias e minoritárias (KORNAI, 2013). No entanto, a utilização da rede mundial de computadores também tem sido importante no processo de documentação e preservação de línguas ameaçadas,

1 Para mais informações sobre a escala EGIDS, ver https://www.ethnologue.com/about/language-status. Acesso em: 29 maio 2020.

2 Reproduzido de: https://www.ethnologue.com/profile/BR. Acesso em: 29 maio 2020.

3 Isto é, aquelas que usufruem de maior circulação, poder e status, como o português e o inglês. 
servindo tanto como plataforma para páginas institucionais dedicadas ao arquivamento de textos orais e escritos quanto como suporte para iniciativas, individuais ou coletivas, que visam incentivar o uso dessas línguas em ambientes digitais. Nesse cenário, páginas da Web, blogs, fóruns, redes sociais online e aplicativos de mensagens têm sido usados como "praças virtuais"4 nas quais línguas minoritárias ganham voz, com importantes implicações para a sua conservação e o seu revigoramento.

Neste trabalho, é discutida a importância do estímulo à utilização de línguas minoritárias em ambientes virtuais, além de serem apresentados casos em que a Web tem se mostrado uma ferramenta eficaz de suporte à preservação e à revitalização de línguas em perigo ao redor do planeta. Parte-se do pressuposto de que a expansão do acesso à Internet no Brasil e no mundo é uma realidade irreversível, o que torna necessária a utilização dos novos recursos em favor da salvaguarda do patrimônio linguístico da humanidade.

\section{A PRESENÇA DE LÍNGUAS MINORITÁRIAS NA WEB E NAS REDES SOCIAIS ONLINE}

As redes sociais online, como o Facebook, o Instagram e o Twitter, são um fenômeno característico das primeiras décadas do século XXI. Por meio dessas ferramentas, indivíduos são capazes de se comunicar, se informar e se engajar, além de se organizar em comunidades e grupos virtuais. Uma das peculiaridades dessas redes é sua natureza colaborativa e, até certo ponto, descentralizada. Esse aspecto é inerente ao que foi chamado de Web 2.0, termo que "se refere ao uso social da Web que permite que as pessoas colaborem, se envolvam ativamente na criação de conteúdo, gerem conhecimento e compartilhem informações online" (GROSSECK, 2009, p. 478, tradução minha5). Assim, os usuários de redes sociais online não são apenas meros consumidores de informação: são, acima de tudo, criadores e disseminadores de conteúdo - conteúdo que, dessa forma, passa a refletir as experiências, interesses e práticas cotidianas de quem os criou e compartilhou. Como acrescentam Warren e Jennings (2015), com o aumento da acessibilidade à Internet pela sociedade, "as redes sociais se tornaram um modo-chave de envolvimento, que permite que as pessoas se comuniquem e compartilhem interesses de muitas maneiras diversas" (p. 140, tradução minha6).

4 O uso do termo "praças virtuais" neste contexto me foi sugerido pela Profa. Dra. Ana Maria Chiarini.

5 Trecho original: "IWeb 2.0] refers to the social use of the Web which allow people to collaborate, to get actively involved in creating content, to generate knowledge and to share information online".

6 Trecho original: "social networking has become a key mode of engagement, which enables people to communicate and share interests in many more ways". 
Antes do surgimento das redes sociais online, diversas iniciativas ao redor do mundo já existiam com a finalidade de documentar ou simplesmente de promover o uso de línguas minoritárias na Web. Warren e Jennings (2015, p. 135), por exemplo, mencionam que uma das primeiras páginas da Internet em jèrriais ${ }^{7}$ foi lançada em 1998 com a única intenção de inserir material na língua em domínio público. No mesmo ano, foi lançada a primeira página que utilizou a escrita uigur ${ }^{8} \mathrm{e}$, no ano seguinte, a primeira página utilizando a escrita tibetana $^{9}$ (ZHIJUAN; XIAOBING, 2019, p. 117). Frequentemente, esses sites "pioneiros" eram - e, em alguns casos, continuam sendo - iniciativas individuais ou de pequenos grupos e traziam notícias, informações e entretenimento na língua. Contudo, esse modelo de página da Internet criada apenas para consumo passivo dos visitantes possui a desvantagem de não permitir grande interação entre os falantes ${ }^{10}$ : elas funcionam como um jornal ou uma revista, promovendo, de modo geral, apenas um contato receptivo (e não ativo, produtivo) com a língua.

Assim, pelo menos a partir desse ponto de vista, o surgimento das redes sociais online abre novas possibilidades - justamente em função, como dito anteriormente, de seu caráter colaborativo e descentralizado. Na avaliação de De Graaf, Van der Meer e Jongbloed-Faber (2015, p. 149), são dois os principais benefícios do uso de línguas minoritárias em redes sociais online. Em primeiro lugar, observa-se o fortalecimento do registro escrito informal da língua"1, pois os falantes passam a ter, mais frequentemente, contato com textos do cotidiano produzidos na língua: mensagens informais, brincadeiras, relatos simples etc. Acrescento que, com o aumento na facilidade de acesso a equipamentos portáteis que possibilitam a gravação de áudios e vídeos, como smartphones e tablets, também o uso do registro oral da língua se intensifica: graças a esses equipamentos, é cada vez mais simples publicar os mais diversos tipos de conteúdo audiovisual, dentre os quais mensagens de áudio curtas, pequenos vídeos etc. O segundo benefício mencionado pelos autores é o reforço do senso de pertencimento a um grupo linguístico minoritário - o que se dá sobretudo em função da percepção da própria língua como um instrumento de valorização identitária. Esse benefício, em particular, acentua-se graças à influência que as novas tecnologias de interação na Web parecem gozar entre falantes jovens, à primeira vista mais atraídos pelas redes sociais online e que são considerados o principal motor para a revitalização de uma língua.

7 Ou jersês, língua falada na dependência britânica de Jersey.

8 Sistema de escrita utilizado para escrever o vigur, língua falada no oeste da China e na Ásia Central.

9 Sistema de escrita utilizado para escrever o tibetano, língua falada na região histórica do Tibete.

10 Neste texto, sempre que são mencionados os "falantes" de uma língua, incluem-se também os sinalizadores de línguas de sinais.

11 Em seu estudo, os autores avaliam o caso específico do frísio, língua germânica que utiliza a escrita. Esse benefício, naturalmente, não se aplica para línguas que não utilizam a escrita. 
Como ilustração do uso de línguas minoritárias em redes sociais online, a Figura 1 mostra a presença de duas línguas indígenas brasileiras em publicações no Instagram e no Facebook contendo code-switching (alternância de códigos), isto é, a utilização de mais de uma língua (no caso, a língua indígena e o português) no mesmo ato comunicativo. Casos como esses são abundantes e podem ser encontrados por meio de simples buscas nas próprias redes sociais. No entanto, observa-se que, em muitas situações ${ }^{12}$, a interação nesses grupos se dá em português, com conteúdo apenas eventual na língua minoritária.
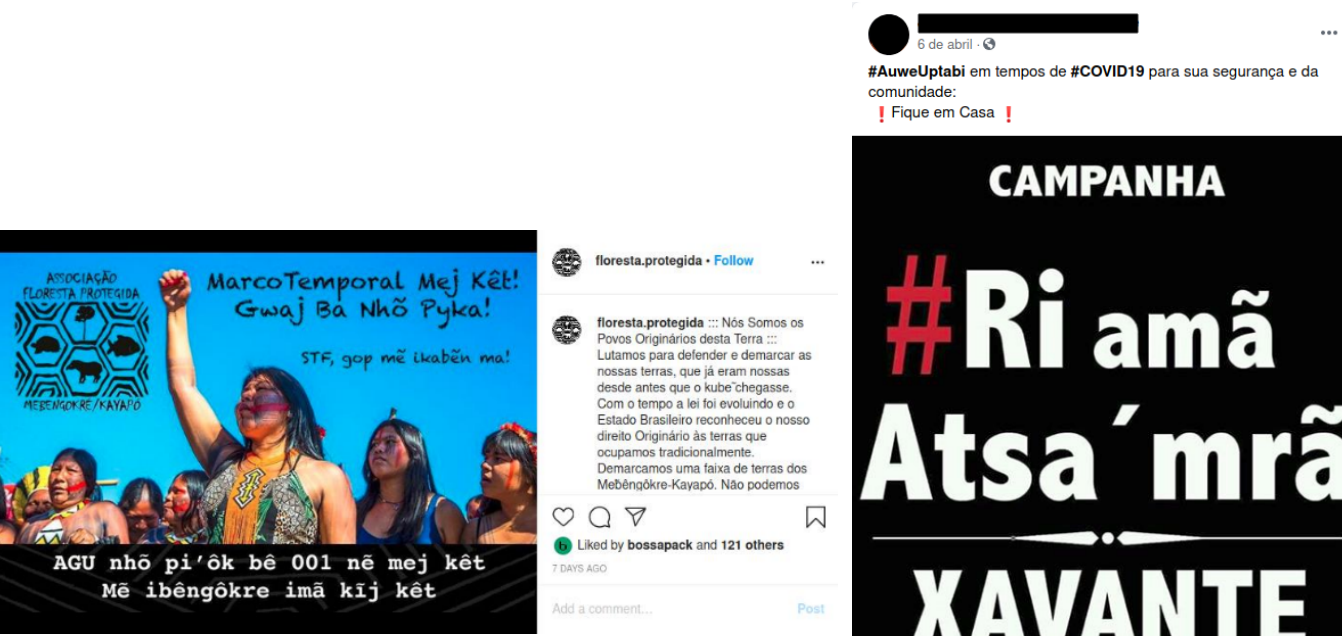

! Fique em Casa !

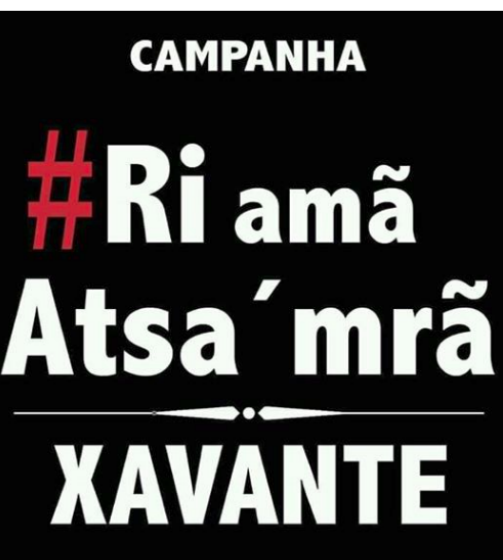

(1) 7

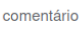

B Curtir

$\diamond$ Compartilhar

we uptabidi Ri re aihoimana

Curtir - Ver traduçăo .4 semanas.

Figura 1. Publicações contendo code-switching (alternância de códigos linguísticos) no Instagram (no perfil público "floresta.protegida") e no Facebook (no grupo público "Etnia XAVANTE A'wẽ Uptabi ("Povo Verdadeiro"),"). A imagem à esquerda contém texto em mebêngôkre/kayapó ${ }^{13}$ e a imagem à direita em akwén/xavante ${ }^{14}$. Nomes e fotos de perfis individuais das redes sociais foram suprimidos para preservação de anonimato. Data de realização das capturas de tela: 29 maio 2020 .

Outro tipo de ferramenta que tem ganhado grande importância são os aplicativos de mensagens instantâneas para smartphones, como o Telegram e o WhatsApp. Diferentemente das redes sociais online mencionadas acima, esses aplicativos possuem um caráter mais privado, em geral não permitindo o acesso de terceiros a conversas particulares ou a grupos de discussão. Ali, são trocadas mensagens de texto (mais uma vez fortalecendo o registro escrito da língua) e de áudio (fortalecendo o registro oral), e até mesmo chamadas

12 O uso de "em muitas situações" é propositalmente vago aqui, pois não foi realizada uma inspeção quantitativa a respeito do uso de línguas indígenas brasileiras em redes sociais online. Essa seria, certamente, uma interessante contribuição para o levantamento do grau de vitalidade dessas línguas em ambientes da Web.

13 Língua falada ao sul do estado do Pará e ao norte do estado do Mato Grosso.

14 Língua falada na região Centro-Oeste do Brasil. 
por vídeo podem ser efetuadas. Além disso, uma característica própria desses meios de comunicação é a possibilidade do compartilhamento de imagens contendo elementos textuais associados, criando, assim, enunciados multimodais.

O uso do WhatsApp como forma de comunicação entre os guaranis do Mato Grosso do Sul é estudado por Franco e Martins (2019), que buscam compreender como a língua é usada nesse contexto, no seu uso real e dentro da sua prática social, em particular no que diz respeito ao fenômeno da variação linguística. Segundo os autores ${ }^{15}$, que estudam um grupo de WhatsApp de uma família extensa, as interações são ricas em abreviações, reduções, empréstimos linguísticos e neologismos próprios dos meios de comunicação digital e, mesmo com as limitações do teclado dos smartphones (que não possuem teclado adaptado para a ortografia do guarani), os usuários encontram estratégias para efetuar a comunicação de maneira satisfatória. Os autores acrescentam que o uso do WhatsApp tem sido importante tanto para a comunicação local quanto para a comunicação entre parentes que vivem em outras localidades, o que vem incentivando aqueles que não falam a língua a passarem a aprendê-la.

Junto a tudo isso, surgem também possibilidades de uso de plataformas para publicação e compartilhamento de vídeos (como o YouTube) e gravações de áudio (como o SoundCloud), que podem ser importantes para a divulgação e a preservação de gravações de cantos, danças, narrativas, rituais - ou, naturalmente, de qualquer conteúdo audiovisual. Tem crescido, inclusive, a presença de canais de indígenas no YouTube, alguns deles versando, inclusive, em questões linguísticas. A título de exemplo, menciono o canal de Cauã $W_{i r a p a y e ́}{ }^{16}$, que inclui séries de vídeos sobre o nheengatu ${ }^{17}$, inclusive videoaulas. Ao se observar os comentários dos espectadores de seus vídeos, fica claro o interesse, seja por parte de indígenas, seja por parte de não-indígenas, pelo conteúdo apresentado. Há diversos outros casos similares, mas com frequência essas videoaulas são esparsas e apenas muito introdutórias, impedindo que uma pessoa interessada em estudar determinada língua pelo YouTube alcance um nível razoável de proficiência.

Ferreira, Machado e Senra (2019, p. 176) observam que o aumento da presença de smartphones nas comunidades faz com que "[o]cupar esses novos espaços sociais e de mídias que se apresentam deve ser encarado como estratégico para o futuro das línguas Yanomami” (p. 176). O mesmo raciocínio se aplica a todas as situações em que esse tipo de equipamento esteja presente, de maneira a atenuar os impactos negativos que o acesso a línguas majoritárias pode ter para a manutenção de uma língua minoritária.

15 Em entrevista disponível em: https://youtu.be/Bmt8a9CdAcs. Acesso em: 22 set. 2020.

16 Disponível em: https://www.youtube.com/channel/UCQIXkFoun22mzyGbDilstvQ. Acesso em: 22 set. 2020.

17 Língua falada na região do Alto Rio Negro. 


\section{ALGUNS PROJETOS E INICIATIVAS DE PRESERVAÇÃO E REVITALIZAÇÃO LINGUÍSTICA NA INTERNET}

Além de contribuir para a interação entre falantes de línguas minoritárias em redes sociais online e em aplicativos de comunicação instantânea, a Internet tem exercido papel fundamental em diversos projetos que visam a documentação, o armazenamento e a divulgação de material linguístico e de informações sobre línguas ameaçadas, tanto no Brasil quanto no exterior. Essas iniciativas variam em abrangência, foco, complexidade e objetivos: algumas se concentram em línguas de uma determinada região ou família linguística, ou contêm apenas determinado tipo de conteúdo (áudio, ou vídeo, ou texto etc.). O Quadro 1 elenca e descreve alguns desses projetos com presença na Web que possuem como objetivo a documentação de línguas minoritárias. É importante salientar que a lista apresentada aqui não é (e nem pretende ser) exaustiva, mas apenas exemplificativa, e que diversas outras iniciativas igualmente relevantes não foram incluídas no quadro - tendo em vista que a intenção, aqui, é levar ao conhecimento do público apenas um panorama geral desse cenário.

Projeto/Iniciativa

Archive of the Indigenous Languages of Latin America (AILLA)

Biblioteca Digital Curt Nimuendajú

Digital Language Diversity Project (DLDP)

Endangered Language Archive (ELAR)

Endangered Languages Project

Living Archive of Aboriginal Languages

Projeto de Documentação de Línguas Indígenas (Prodoclin)

\section{Descrição/Informações}

Um arquivo digital de gravações, textos e outros materiais multimídia em e sobre línguas indígenas da América Latina. Página oficial: https://ailla.utexas.org/. Acesso em: 25 set. 2020

A Biblioteca Digital Curt Nimuendajú, como consta em sua página, é "um repositório de recursos sobre línguas e culturas indígenas sul-americanas, incluindo livros raros, artigos, dissertações e teses, com o objetivo de tornálos mais acessíveis a pesquisadores e outros interessados". Página oficial: http://www.etnolinguistica.org/. Acesso em: 25 abr. 2020.

Focado em línguas minoritárias europeias, visa promover a diversidade linguística em contextos digitais. Seus principais objetivos são pesquisar o uso e linguas minoritárias na Web e fornecer orientações para que falantes dessas línguas criem conteúdo digital e materiais para ensino e aprendizado online. Página oficial: http://www.dldp.eu/. Acesso em: 13 abr. 2020.

Repositório digital que publica informações e preserva material (áudio, vídeo, texto) de línguas ameaçadas de todo o mundo, inclusive de diversas línguas dos povos originários do Brasil. Página oficial: https://elar.soas.ac.uk/. Acesso em: 22 set. 2020.

Em sua página, consta que o projeto "é um recurso on-line para amostras e pesquisas sobre idiomas em risco de extinção. Ele também é uma forma de compartilhar conselhos e melhores práticas com pessoas que trabalham para fortalecer a diversidade linguística". Entre os recursos disponíveis na página, há vídeos, áudios e documentos em diversas línguas ameaçadas, além de informações básicas sobre mais de 3.000 línguas. Página oficial: http://www.endangeredlanguages.com/. Acesso em: 17 abr. 2020.

A Oceania é uma das regiões do mundo com maior número de línguas indígenas ainda vivas. O Living Archive of Aboriginal Languages é um repositório digital de informações e conteúdo em línguas aborígenes do Território do Norte (Northern Territory) da Austrália. Ele surgiu a partir da necessidade de se agregar, de maneira organizada e sistemática, materiais sobre essas línguas que se encontravam, anteriormente, dispersos e fragmentados, dificultando o acesso por parte de falantes, pesquisadores e público em geral. Página oficial: https://livingarchive.cdu.edu.au/. Acesso em: 25 abr. 2020.

Na página deste projeto desenvolvido pelo Museu do Índio consta material audiovisual e etnográfico sobre algumas línguas indígenas brasileiras que foram documentadas. Página oficial: http://prodoclin.museudoindio.gov.br/. Acesso em: 22 set. 2020.

Quadro 1. Alguns projetos e iniciativas visando documentação e manutenção linguística na Internet. 
Para fins de ilustração, a Figura 2 mostra a página dedicada ao xokleng ${ }^{18}$ no portal do Endangered Languages Project. Na data em que foi obtida a captura de tela, havia dois vídeos disponíveis, dentre os quais a gravação de uma canção xokleng.

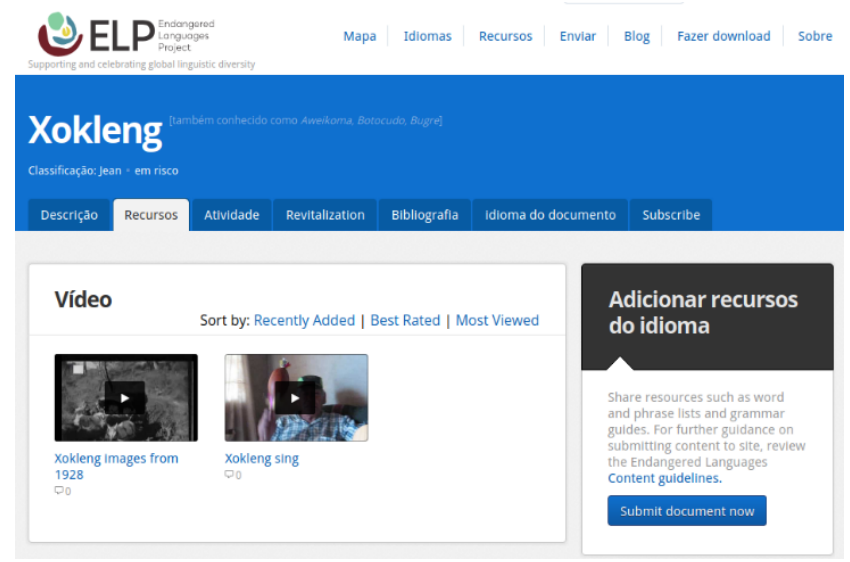

Figura 2. Página dedicada ao xokleng no portal do Endangered Languages Project. Fonte: http://www.endangeredlanguages.com/lang/1650/guide?hl=pt-br. Acesso em: 07 jun. 2020.

Iniciativas como as elencadas acima são fundamentais para a valorização e a documentação de línguas ameaçadas, ajudando a fomentar e a fortalecer pesquisas sobre elas e sobre os povos que as falam. Entretanto, "[u]ma língua se mantém viva e forte se ela acompanha os processos de mudanças sociais e está presente nos novos espaços da vida da comunidade falante" (FERREIRA; MACHADO; SENRA, 2019, p. 169), razão pela qual é importante que ela não apenas seja registrada, mas sobretudo que ela faça parte das diversas situações do cotidiano de seus falantes.

\section{OBSERVAÇÕES E REFLEXÕES}

Estar presente na Internet significa ocupar um espaço de poder social, político e econômico considerado essencial no "mundo contemporâneo ocidental". Para uma língua, isso pode significar um ganho substancial de prestígio e de estima por parte de seus próprios falantes. Línguas minoritárias, sobretudo em um país como o Brasil, tendem a ser discriminadas e a receber pouca exposição na mídia e nos meios políticos, muitas vezes não sendo sequer consideradas línguas e sendo chamadas simplesmente de "dialetos". O advento da Internet e das mídias digitais abriu portas para a disseminação de conteúdos gerados por indivíduos e para a comunicação mediada por computadores, permitindo, assim, que algumas dessas 
línguas recebam um sopro de vitalidade. Como ilustração do reconhecimento que uma língua pode obter ao adentrar no "mundo da tecnologia", Warren e Jennings (2015, p. 137) contam que "a revelação de que uma versão do Facebook em jèrriais estava em preparação despertou grande interesse da mídia local, (...) relatando que a língua de Jersey estava caminhando para o século XXl" (tradução e grifo meus ${ }^{19}$ ).

Um ponto fundamental nesta discussão é a necessidade de se promover o uso da língua em todos os aspectos da vida de seus falantes. É bem sabido que não basta apenas ensinar a língua na escola e esperar que as crianças e os jovens passem a utilizá-la no cotidiano: para realmente preservá-la e revitalizá-la, é preciso que ela faça parte do dia a dia de quem a fala. Isso é ilustrado na Figura 3, que reproduz uma publicação de alerta e orientação acerca do coronavírus escrita em tikuna ${ }^{20}$ e compartilhada na Web: trata-se de um caso em que a língua foi usada com finalidade informativa, o que a torna parte do cotidiano dos falantes. Conforme sugerem Ferreira, Machado e Senra (2019, p. 169), "é sinal de vigor e relevância social a língua que circula pelos meios de comunicação que são efetivamente usados pela comunidade linguística, tanto os escritos (...) como os audiovisuais, como radiofonia, rádio e TV”. Acrescento, aqui, também a Internet.

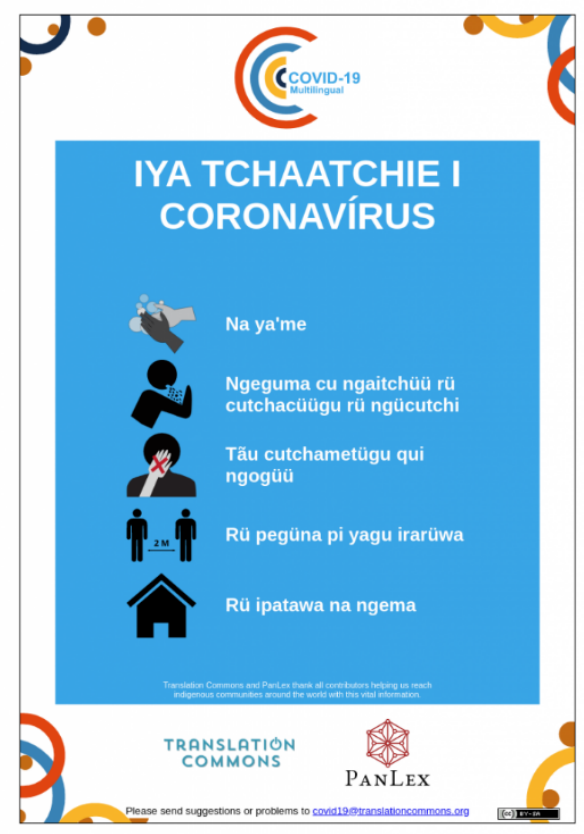

Figura 3. Publicação de alerta e orientação acerca do coronavírus escrita em tikuna e compartilhada na Web. Reproduzido de: http://kamuri.org.br/kamuri/em-lingua-tikuna-os-parentes-sao-alertados/. Acesso em: 06 jun. 2020.

\footnotetext{
19 Trecho original: "[t]he revelation that a Jerriais version of Facebook was in preparation excited a great deal of interest in the local media, (...) reporting that Jersey's own language was moving into the twenty-first century". 20 Língua falada na região amazônica.
} 
Com relação ao uso de redes sociais e aplicativos de comunicação instantânea para auxiliar no fortalecimento de uma língua minoritária em uma comunidade bilíngue, algumas ideias podem vir da área de ensino de línguas estrangeiras. Diversas práticas podem ser adaptadas, como, por exemplo, a criação de grupos no WhatsApp (ou em outro aplicativo utilizado na comunidade) dedicados ao uso da língua. Textos, imagens, vídeos e áudios podem ser criados e compartilhados. A depender do nível de domínio da língua por parte dos falantes, pode-se determinar que o grupo é 100\% dedicado à língua (isto é: línguas majoritárias, como o português, não podem ser usadas de forma alguma), ou, então, estipular que um ou mais dias da semana são inteiramente dedicados à interação na língua, deixando os demais dias livres. Uma iniciativa como essa é simples e funciona como um grupo de conversação e prática no formato assíncrono, sem a necessidade de encontros ao vivo com a presença de todos ao mesmo tempo. Os membros do grupo, em particular os mais jovens, podem ser estimulados a criarem conteúdo na língua, como, por exemplo, conteúdo em formato de "meme" (imagem + texto) ou pequenos vídeos para serem compartilhados no próprio grupo e em outras redes sociais. É importante que uma iniciativa assim seja apreciada pelos jovens, que são o motor da revitalização linguística. Tudo isso pode ser explorado nas escolas indígenas ou mesmo na comunidade como um todo. A essência da revitalização e da manutenção de línguas é a mesma: interação e engajamento em situações do cotidiano, do mundo real, em práticas normais do dia a dia.

Ferramentas digitais também facilitam o contato entre ativistas pela preservação de línguas diferentes, que podem estabelecer contatos com outros grupos e indivíduos dedicados à preservação de línguas ameaçadas e ter acesso aos seus projetos e iniciativas. Assim, iniciativas bem sucedidas podem ser reproduzidas e erros podem ser evitados.

Finalmente, é necessário sempre levar em consideração que as línguas minoritárias, ou mesmo as línguas ameaçadas, formam um grupo muito heterogêneo: enquanto há línguas que se beneficiariam só de estarem presentes em um grupo de Facebook, há aquelas que, neste momento, se beneficiariam mais de programas de computador para tarefas como tradução automática, sumarização de textos ou correção ortográfica e gramatical para editores de texto. Mesmo para estas, o desafio é grande. Hiortnaes (2019) apresenta uma situação hipotética que pode contribuir diretamente para a diminuição no uso de uma língua:

Sempre que alguém desejar usar seu telefone ou outro dispositivo ativado por voz e este não estiver na língua materna do indivíduo, ele deverá mudar para uma língua disponível. (...) A alternância entre línguas exige muito esforço cognitivo. (...) E incorporar tecnologias linguísticas está se tornando cada vez mais predominante. Portanto, se você é falante de uma língua que não está disponível em um determinado dispositivo, em que momento você simplesmente para de 
usar sua língua materna e simplesmente alterna para a língua mais comum na qual você é competente? (HJORTNAES, 2019, tradução minha ${ }^{21}$ )

É fundamental enfatizar que o uso da Internet também pode trazer problemas para uma comunidade. Entre eles, destaco a vigilância das atividades dos usuários da Web - que pode ser levada a cabo pelas empresas provedoras dos serviços (por exemplo, o Facebook), que coletam os dados dos usuários para os mais diversos fins; ou, ainda, pelos próprios governos. Ligado a isso, há também a questão dicotômica entre direito à privacidade versus o excesso de exposição nas redes. Porém, essas questões não se aplicam apenas a falantes de línguas minoritárias, mas também à toda a comunidade de usuários de plataformas na Web.

\section{CONSIDERAÇÕES FINAIS}

Neste artigo, são apresentadas algumas considerações a respeito da utilização da Web como uma ferramenta de suporte à preservação e à revitalização linguística. A ideia fundamental consiste no fato de que, diante da efetiva ameaça de desaparecimento que sofrem, na atualidade, milhares de línguas ao redor do mundo, todos os instrumentos para a conservação da diversidade linguística devem ser explorados. A Internet possui um papel paradoxal nesse contexto, pois, ao mesmo tempo em que contribui para a disseminação de línguas majoritárias e hegemônicas (como o inglês e o português) para cada vez mais indivíduos e comunidades, pode auxiliar a ampliar a voz dos falantes de línguas minoritárias. Para ilustrar esse fato, é apresentada aqui uma pequena coletânea de projetos e iniciativas virtuais que possuem como objetivo a documentação, a preservação e a revitalização de línguas ameaçadas no Brasil e no mundo, além de alguns casos selecionados que exemplificam como as redes sociais online podem ser úteis nesse processo.

O principal objetivo deste artigo é sustentar que o uso de uma língua em ambientes digitais pode propiciar-lhe prestígio em virtude da valorização provocada pela sua presença no cenário global da Internet, resultando assim na ampliação da estima dos falantes pela própria língua. Entende-se que este tópico é bastante relevante, mas ainda pouco discutido no contexto dos debates contemporâneos referentes à manutenção e revitalização de línguas, especialmente no que diz respeito às línguas dos povos originários das Américas e do Brasil, em particular. Apesar do cenário de incertezas, a Web pode oferecer caminhos,

21 Trecho original: "Any time someone wants to use their phone or other voice activated device and it is not in their native language, they must switch to a language that is available. (...) [S]witching languages takes a lot of cognitive effort (...). And incorporating language technology is only getting more and more prevalent. So if you're a speaker of a language that isn't available on your tech, at what point do you just stop speaking your native language and just switch to the more common one you're pretty proficient at?' 
oportunidades e possibilidades para o suporte à manutenção da vitalidade de línguas em perigo, contribuindo, assim, para a promoção da diversidade linguística e para a salvaguarda desse patrimônio imaterial da humanidade. Segundo D’Angelis,

\begin{abstract}
qual é o impacto de os jovens não verem sua língua na internet? (...) Não ver sua língua na internet, naquilo que lhe parecerá o maior espaço de divulgação e circulação de idéias e informações, só acarretará em um enorme número de crianças e jovens indígenas um desprezo por sua tradição cultural, e arraigará neles a convicção de que a língua de seus antepassados não tem papel ou função no mundo moderno. (D’ANGELIS, 2008, p. 4)
\end{abstract}

Essa situação deve ser evitada ao máximo possível.

Por fim, é importante reforçar a necessidade de se discutir o problema da ameaça à diversidade linguística no planeta, além de se propor meios para ao menos atenuar essa situação. A consolidação das redes sociais online e das formas de comunicação por meio de ferramentas digitais é, sem dúvida, um caminho sem volta, motivo pelo qual a valorização das línguas minoritárias nesses espaços parece ser um caminho promissor para a preservação e a revitalização de pelo menos uma parte das línguas minoritárias em perigo de extinção.

\title{
5. AGRADECIMENTOS
}

Este trabalho foi realizado com apoio da Coordenação de Aperfeiçoamento de Pessoal de Nível Superior (CAPES), código de financiamento 001, e do Conselho Nacional de Desenvolvimento Científico e Tecnológico (CNPq). Agradeço à Profa. Dra. Ana Vilacy M. Galucio pelos comentários, críticas e diversas sugestões à versão preliminar deste artigo.

\section{REFERÊNCIAS}

D’ANGELIS, Wilmar da R. Do índio na Web à Web Indígena. 2010. Disponível em: http://www.webindigena.org/Imagens/Noticias/Arquivos/Do\%20Indio\%20na\%20Web\%20\%C3\%A0\%20Web\%20I ndigena.pdf. Acesso em: 29 maio 2020.

DE GRAAF, Tjeerd; VAN DER MEER, Cor; JONGBLOED-FABER, Lysbeth. The use of new technologies in the preservation of an endangered language: the case of Frisian. In: JONES, Mari C. (Ed.). Endangered languages and new technologies. Cambridge: Cambridge University Press, 2015, p. 141-149.

EBERHARD, David M.; SIMONS, Gary F.; FENNIG, Charles D. (Eds.) Ethnologue: languages of the world. 23rd ed. Dallas: SIL International, 2020. Versão online: http://www.ethnologue.com. Acesso em: 29 maio 2020.

FERREIRA, Helder P.; MACHADO, Ana Maria A.; SENRA, Estêvão B. (Orgs.) As línguas Yanomami no Brasil: diversidade e vitalidade. São Paulo: Instituto Socioambiental (ISA); Boa Vista: Hutukara Associação Yanomami (HAY), 2019.

FISHMAN, Joshua A. (Ed.) Can threatened languages be saved? Reversing language shift, revisited: A 21st century perspective. Clevedon: Multilingual Matters, 2001. 
FRANCO, Flaviano; MARTINS, Andérbio M. S. Letramento digital móvel entre os guarani de Mato Grosso do Sul: um estudo sobre as variações linguísticas registradas no WhatsApp. In: ENCONTRO DE ENSINO, PESQUISA E EXTENSÃO (ENEPEX), 2019. Anais [...]. Disponível em:

http://eventos.ufgd.edu.br/enepex/anais/arquivos/3524.pdf. Acesso em: 22 set. 2020.

GROSSECK, Gabriela. To use or not to use web 2.0 in higher education? Procedia - Social and Behavioral Sciences, v. 1, n. 1, p. 478-482, 2009. doi.org/10.1016/i.sbspro.2009.01.087

HINTON, Leanne. Language revitalization: an overview. In: HINTON, Leanne; HALE, Kenneth (Ed.). The green book of language revitalization in practice. Leiden: Brill, 2001, p. 3-18.

HJORTNAES, Nils. The importance of tech in language revitalization, 2019. Disponível em https://blog.linguistlist.org/fund-drive/the-importance-of-tech-in-language-revitalization/. Acesso em: 9 abr. 2020.

KORNAI, András. Digital language death. PLOS ONE, v. 8, n. 10, 2013. DOI: https://doi.org/10.1371/journal.pone.0077056

MOORE, Denny; GALUCIO, Ana Vilacy; GABAS JR., Nílson. O desafio de documentar e preservar as línguas amazônicas. Scientific American (Brasil), n. 3, p. 36-43, set. 2008.

MOSELEY, Christopher (Ed.). Atlas of the world's languages in danger. 3ed. Paris: UNESCO, 2010.

WARREN, Anthony S.; JENNINGS, Geraint. 'Allant contre vent et mathée': Jèrriais in the twenty-first century. In: JONES, Mari C. (Ed.). Endangered languages and new technologies. Cambridge: Cambridge University Press, 2015, p. 127-140

ZHIJUAN, Wang: XIAOBING, Zhao. The state of minority language websites of China. In: YUMING, Li; WEI Li (Ed.). The language situation in China, v. 5. Berlin: De Gruyter Mouton, 2019, p. 117-128. 